\title{
Photon-phonon synergy: photoacoustic tomography and beyond (Presentation Video)
}

Lihong Wang

Lihong V. Wang, "Photon-phonon synergy: photoacoustic tomography and beyond (Presentation Video)," Proc. SPIE 9323, Photons Plus Ultrasound: Imaging and Sensing 2015, 93235K (22 April 2015); doi: 10.1117/12.2197205 


\title{
Photon-phonon synergy: photoacoustic tomography and beyond (Presentation Video)
}

\author{
Lihong V. Wang, Washington University in St. Louis (USA)
}

\begin{abstract}
Photoacoustic tomography is expected to impact biology and medicine broadly by providing multiscale in vivo functional and molecular imaging of structures ranging from subcellular organelles to organs, enabling a noninvasive look at subcutaneous tissue at a deep level.
\end{abstract}

View presentation video on SPIE's Digital Library: http://dx.doi.org/10.1117/12.2197205.4093523002001 